analecta polit. | Vol. 9 | No. 16 | PP. 151-170 | enero-junio | 2019 | ISSN-e: 2390-0067 (en línea) |

Medellín-Colombia

doi: http://dx.doi.org/10.18566/apolit.v9n16.a08

\title{
Voluntad general y Revolución
}

General will and Revolution

Vontade geral e revolução

\section{JACINTO H. CALDERÓN GONZÁLEZ}

Doctor en Filosofía

Pontificia Universidad Javeriana, Bogotá - Colombia.

Correo electrónico: jacintohache@yahoo.es orcid.org/0000-0003-0940-2519 


\section{Resumen}

El presente artículo pretende poner de relieve, en el marco de la interpretación de la toma del poder en una revolución, las contradicciones, los aciertos, las aporías y los modos de ser de la vida política en El contrato social de Rousseau, atendiendo, especialmente, a los conceptos de "voluntad general", "libertad" e "igualdad". Se pretende, de igual manera, hacer una reflexión sobre el significado de esos conceptos asociados a la posibilidad de la revolución y a cómo se podrían implantar en ese contexto, atendiendo a los medios de su realización (en especial el terror).

Palabras clave: contrato social, voluntad general, libertad, revolución, terror.

\section{Abstract}

This article tries to highlight the contradictions, successes, aporias and ways of being of political life in Rousseau's Social contract, in the framework of the interpretation of the taking of power in a revolution. Special attention is given to the concepts of "general will", "freedom" and "equality". It is also intended to reflect on the meaning of those concepts associated with the possibility of revolution and how they could be implemented in such a context, taking into account the means for its realization (especially terror).

Keywords: social contract, general will, freedom, revolution, terror.

\section{Resumo}

Este artigo pretende por de realce, no marco da interpretação da tomada do poder em uma revolução, as contradiçóes, os acertos, as aporias e as maneiras de ser da vida política em O contrato social de Rousseau, pondo o foco principalmente nos conceitos de "vontade geral", "liberdade" e "igualdade". Pretende-se, assim mesmo, fazer uma reflexão ao respeito do significado desses conceitos associados à possibilidade da revolução e aos meios pelos quais poderia se implantar nesses contextos, fazendo uso dos meios para sua realização (especialmente o terror)

Palavras-chave: contrato social, vontade geral, liberdade, revolução, terror. 


\section{Introducción}

Hemos de decir que, a lo largo de la historia de las ideas políticas, algunos filósofos han tenido más repercusión que otros $y$, a ojos vistas, hemos de conceder que uno de los que mayor influencia ha ejercido y que, de hecho, sigue ejerciendo, es Jean-Jacques Rousseau. Su influencia reside ante todo en la concepción, diremos radical, de la libertad y de la necesidad de realizarla en clave política. Tanto es así que podemos decir que sus ideas conformaron los ideales más libertarios de la Revolución francesa y que, con ellas, contribuyó a su propia radicalización.

En efecto, las ideas fundamentales de Rousseau están contenidas en el espíritu de la Revolución ${ }^{1}$ y son, de alguna manera, indispensables si queremos entender los diversos fenómenos que ocurrieron en esa época. Pensemos en el propio comienzo de El contrato social: "El hombre ha nacido libre y en todas partes está encadenado". Explicar por qué se producen estas cadenas y atender a cómo se pueden quitar es el sentido esencial de aquel texto.

En estas líneas queremos tratar de fundamentar la libertad y la igualdad a partir de este texto clásico de la filosofía política, teniendo como punto de partida y llegada la posibilidad de la revolución y lo que esta implica, tanto en la Revolución francesa como hoy en día. Por supuesto, indicar la necesidad del cambio y la posibilidad de nuevos movimientos sociales en el presente supone tener claros ciertos puntos esenciales de los cuales partir y, a su vez, corroborar en qué medida se están cumpliendo, tanto en lo positivo como en lo negativo.

A pesar de los diversos logros sociales (considerados incluso como hechos históricos), nada impide observar que las carencias actuales en lo que refiere a la experiencia no solo de la libertad, sino también de la igualdad, son más reales de lo que a primera vista puede parecer. No queremos tampoco olvidar, en este artículo, la posibilidad de tenerles miedo a las revoluciones por las consecuencias autocráticas que estas suelen producir (de lo que ciertamente se aprovechan las

1 Sobre este particular, la entrada "Rousseau" de Bernard Manin en el Diccionario de la Revolución francesa (Furet, Frances y Ozout, Mona -eds.-, Madrid: Alianza Editorial, 1989) ofrece consideraciones actualizadas sobre qué tanto alcance tuvo la obra de Rousseau en la práctica de la revolución. Hay que considerar, además, que la Revolución francesa fue un evento sin precedentes, tanto por sus dimensiones como por sus cambios radicales. Esta ausencia de precedentes le dio un marco amplio de innovación e, incluso, de improvisación. Por eso, la teoría de Rousseau resulta valiosa y, como recuerda Manin, "Rousseau no es el 'legislador' de la Revolución, pero ejerce sobre ella lo que podría denominarse un magisterio de opinión" (p. 720). 


\section{4 | Jacinto H. Calderón González \\ Voluntad general y Revolución}

elites dirigentes para mantener dócil a la población). En este sentido, se esboza una crítica también a ciertas teorías sobre la revolución que, a la postre, sitúan al individuo en un contexto triste, pues tras haber luchado por su libertad, la pierde formando un Estado que lo oprime con más fuerza.

\section{Libertad}

Decir que Rousseau es uno de los principales defensores de la libertad es quedarse corto, dado que su lado más radical supondrá, como veremos, que sin libertad no hay humanidad y que perderla, o sea, no ser libre, es dejar de ser hombre.

Berlin se pregunta por el motivo por el cual un filósofo que, a la postre, repetía ideas que desde Hobbes eran ya canónicas en la teoría política, pudo tener tanta repercusión. Los motivos son múltiples: su estilo incendiario, su prosa abierta, "algunos podrían decir que efectuó una reconciliación entre la libertad individual y la autoridad de la comunidad" 2 o su radicalidad manifiesta.

Sin embargo, mejor es analizar las ideas de sus textos. El contrato social, publicado en 1762, parte del hecho contradictorio de que el hombre, naciendo libre, se encuentra siempre encadenado. Y no porque haya nacido sometido a esclavitud perpetua, sino por el hecho más crucial de que no sabe cómo salirse de las cadenas a las que su propia libertad lo conduce. La ausencia de libertad no influye únicamente en el paria, el descamisado o el miembro del Tercer Estado. No, las cadenas afectan incluso a los que tienen poder: "hay quien se cree señor de los demás y es más esclavo que ellos"3. La pregunta, para Rousseau, era evidente: ¿qué ha conducido al hombre a esta situación? Responder este interrogante es uno de los retos que debe solucionar el autor de El contrato social. Interrogante ciertamente coherente. Si las diversas constituciones políticas de nuestra época histórica nos garantizan la libertad, ¿por qué sentimos íntimamente que nos la han robado o que ha quedado relegada a una mera libertad de consumo?

Rousseau hace hincapié en la contraposición entre libertad y esclavitud. Si éramos todos libres, se tuvo que dar una suerte de proceso -llámese "lucha" o "guerra"- en que, una vez acabada la libertad, se condujo a unos a seguir siendo libres y a otros a inaugurar una nueva vida bajo el yugo de la esclavitud.

2 Berlin, Isaiah. La traición a la libertad. Seis enemigos de la libertad humana. Fondo de Cultura Económica. México, 2002, p. 51.

3 Rousseau, Juan Jacobo. El contrato social. Gredos, Barcelona. 2014, p. 261. 
Es de sobra conocida la influencia que ejerció Rousseau sobre los idealistas alemanes y, por ello, no es de extrañar que la dialéctica del amo y el esclavo en Hegel tuviera una inspiración roussoniana, al menos en cierto sentido. Hegel parte de la idea de que el hombre, para saber lo que es, para probarse a sí mismo que es un hombre (una autoconciencia, para ser precisos), debe salir de la inmediata naturalidad de la vida para entablar un proceso de reconocimiento con su semejante. Tal proceso no se da de forma pacífica, sino que, como explica Kojeve, "sin esa lucha a muerte hecha por puro prestigio, no habrían existido jamás seres humanos sobre la tierra"4. La naturaleza de la autoconciencia, escribe Hegel, es ser Begierde, o sea, apetencia o deseo, y, desde el prestigio, cabe decirse que el deseo por excelencia, el que nos hace luchar, es el deseo de ser deseado (o sea, ser un objeto de deseo, objetivarse como algo objetivo ante el otro, ser real ante alguien que deja de serlo para que el otro alcance esa dignidad). Puro prestigio, pero que desencadena violencia: pura necesidad de que mi libertad sea reconocida, pero a su vez negación de la libertad del otro. Para Hegel, tal lucha es necesaria para alcanzar humanidad. La libertad obtenida, empero, es negación de la misma, dado que, como decía Rousseau, un amo es tan esclavo como su esclavo, o, como diría Fichte, tal amo doblaría la rodilla ante el primer hombre superior que se encontrare ${ }^{5}$.

Este panorama explicaría de algún modo que nos encontremos rodeados de cadenas, estemos donde estemos: el esclavo pierde toda independencia respecto de sí (no es para él, es para otro), pero el amo pierde también su independencia por la necesidad que tiene del esclavo (y no solo su independencia: su propia estimación sobre el mundo es una mediación a través del trabajo del esclavo). La lucha por la igualdad aparece, en los albores de la humanidad, como la esencia de la abstracción. No puede haber igualdad -se dirá-; de haberla, no habría humanidad posible: es necesaria la guerra para que los más dignos se enseñoreen ante todos. Dura lex, sed lex. Craso error, pero inevitable. La historia de la humanidad es la historia de su propia estulticia.

Rousseau, que más o menos se podría haber imaginado la dialéctica del amo y el esclavo de Hegel, supone que el pueblo subyugado tiene que obedecer y mientras obedece bajo el yugo "obra bien", pero "tan pronto como puede sacudir el yugo, y lo sacude, obra aún mejor; pues, al recobrar su libertad por el mismo derecho con que le fue arrebatada, o tiene razón para reivindicarla, o no la tenían para quitársela" ${ }^{\circ}$.

4 Kojeve, Alexander. La dialéctica del amo y del esclavo en Hegel. Leviatan. Buenos Aires, 2012. P. 14.

5 Fichte, J.G. Algunas lecciones sobre el destino del sabio. Itsmo. Madrid, 2002, p. 81.

6 Rousseau, J.J. op. Cit. P. 262. 


\section{6 | Jacinto H. Calderón González \\ Voluntad general y Revolución}

Sin embargo, Rousseau es consciente de que ese quitarse el yugo es algo peregrino, porque la esclavitud se perpetúa por el miedo: "todo hombre nacido en la esclavitud nace para la esclavitud, nada más cierto. Los esclavos lo pierden todo en sus cadenas, hasta el deseo de librarse de ellas". Hegel considera que el medio para que la esclavitud se perpetúe consiste en suponer que el esclavo no es esclavo del amo, sino que es esclavo del miedo, y Rousseau, en la misma línea, escribe: "la fuerza ha hecho a los primeros esclavos, la cobardía de los mismos los ha perpetuado"8.

Ahora bien, ¿la cobardía es eterna en los individuos? No, y esto es importante porque el amo sabe de sobra que si no somete y aterroriza al esclavo (como los ilotas del Peloponeso, o los trabajadores asalariados actuales, con la salvedad de que a estos no los matan directamente, sino que los privan de sus medios de subsistencia), este podría volverse valiente y encabezar una revuelta. Hobbes y Rousseau coinciden en que no habría nadie tan fuerte como para evitar un asesinato en cualquier momento. Por eso, "el más fuerte no es nunca lo bastante fuerte para ser siempre el amo, si no transforma su fuerza en derecho y la obediencia en deber"'. Aquí se encuentra el derecho del más fuerte que no tiene más significación que la fuerza misma y el terror que la acompaña. Pero claro, ¿tal significación podría servir para un orden justo y racional de la humanidad? Desde luego que no, pero históricamente ha servido para mantener atados a los hombres.

Para Rousseau, ceder ante la fuerza es "un acto de necesidad", algo que cualquiera cumpliría sin remilgos: no ceder es morir, pero una muerte que tiene sentido porque actualiza la libertad. Si no hay una fuerza que sujete las cadenas del esclavo, no hay ningún deber que tenga que cumplir este para con el amo. Lo mejor que puede hacer es irse. La cuestión, para Rousseau, es más que pertinente: “¿qué derecho es ese que prescribe cuando la fuerza cesa?”"10. Dicho de otra manera, ¿seguir al que me oprime es un deber para mí? Contestar afirmativamente supondría tener el alma de un perro. Como tal cosa no ocurre, podría parecer que la liberación de las cadenas de la esclavitud es lo que supone un deber, es decir, que liberarse, hacer una revolución, es más un deber que seguir como un borrego las cadenas de la esclavitud: todo hombre se hace hombre cuando busca su libertad y la libertad de su semejante. Así lo expresó Fichte: "sólo es libre aquel que quiere liberar a los que le rodean"11.

\footnotetext{
Ib. P. 263.

8 Ídem.

9 Ib. p. 264.

10 Ídem.

11 Fichte, J. G. Op. Cit. p. 81.
} 
La lucha por la propia libertad es el deber más sagrado que tenemos: "renunciar a la propia libertad es renunciar a la cualidad de hombre, a los derechos de la humanidad, incluso a sus deberes. No hay compensación posible para quien renuncia a todo. Renuncia tal es incompatible con la naturaleza del hombre, y privar de toda libertad a su voluntad es privar de toda moralidad a sus acciones" ${ }^{12}$. La conciencia del esclavo debe variar irremediablemente. Ser esclavo es ser una cosa y, por ello, es preferible la muerte a la pérdida de la libertad. No hay otro camino.

Ahora bien, más allá del análisis de la esclavitud, no vamos a poder decir, en honor de la verdad, que en el siglo de Rousseau -o en los siglos anteriores y posteriores- la sociedad fuera una mezcla de amos y esclavos. Cierto que ha habido momentos en la historia en que tales eventos han sucedido, pero la realidad reviste una crueldad incluso más sutil. ¿ No es cierto que las cadenas invisibles de la sociedad nos atan de una forma similar a las cadenas visibles de la esclavitud? Las sociedades avanzan y el progreso conduce a que la esclavitud no sea directa (al menos en parte). Precisamente, por no haber una esclavitud directa es que se puede hablar ahora de igualdad y contrato social, dado que, en efecto, si la esclavitud es tácita, el pacto no incluiría a los esclavos y perdería su universalidad. Para que el pacto sea efectivo, hace falta igualdad, es decir, la conciencia de que todos los hombres son iguales.

\section{Igualdad y contrato social}

Si queremos definir la igualdad, podríamos adscribir el artículo con el que se abre la Declaración de los derechos del hombre y del ciudadano de 1789: "Los hombres nacen y permanecen libres e iguales en derechos. Las distinciones sociales sólo pueden fundarse en la utilidad común". Como tal, podemos asumir inmediatamente que hablar de igualdad es, al mismo tiempo, hablar de libertad. Y, por supuesto, si queremos tomarnos la libertad en serio, esta solo puede darse donde hay igualdad. Los dos términos se relacionan de forma directa: únicamente soy libre ante mis iguales, las relaciones de superioridad o inferioridad no nos hacen libres en ningún contexto.

Ya desde Aristóteles ${ }^{13}$ sabemos que la construcción de una república que funcione necesita no sólo individuos que sean libres, sino individuos que, más que

12 Ib. P. 266.

13 Cfr. Ética a Nicómaco lb. VIII y IX, Política lb. III. 
iguales, puedan ser amigos. Arendt, suponiendo que el mayor riesgo para una república consiste en la lucha facciosa de sus componentes, nos recuerda que "la

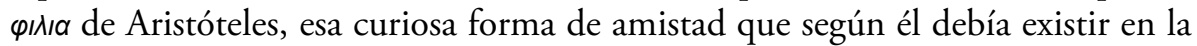
base de las relaciones entre los ciudadanos, fue concebida como el medio más seguro con que defenderse de dicha amenaza" ${ }^{14}$. Aristóteles, por otro lado, había supuesto que la amistad entre hermanos era el modelo del que se podía sacar una república, dado que entre hermanos (al menos si la diferencia de edad no es excesiva) lo que prima es el interés común y la perfecta igualdad, lo cual abre las puertas a la libertad. Para los atenienses, sin ir más lejos, cuando un ciudadano destacaba en exceso, ya fuera por ser demasiado rico o por haber acumulado demasiado poder (Temístocles, Milcíades), no había problema en condenarlo al ostracismo o a otra pena peor.

Ciertamente, la igualdad y la libertad se unen en la fraternidad; para los revolucionarios franceses, esta triada fue asumida y creída por todos (al menos durante un tiempo). Arendt, presumiendo lo que para los revolucionarios franceses $y$, por supuesto, para Rousseau, era un hecho, escribe:

La cuestión social comenzó a desempeñar un papel revolucionario solamente cuando, en la Edad Moderna y no antes, los hombres empezaron a dudar que la pobreza fuera inherente a la condición humana, cuando empezaron a dudar que fuese inevitable y eterna la distinción entre unos pocos, que, como resultado de las circunstancias, la fuerza o el fraude, habían logrado liberarse de las cadenas de la pobreza, y la multitud, laboriosa y pobre ${ }^{15}$.

Si traemos esta idea a colación es porque responde de alguna manera al propósito de Rousseau de emancipar al esclavo de sus cadenas. En efecto, no hay revolución posible si entre los hombres no hay conciencia de igualdad: hazles creer primero que son iguales y, cuando lo sepan, llegarán adonde sea.

En las líneas anteriores, habíamos dejado claro que para Rousseau el derecho del más fuerte no servía para mantener la esclavitud como un estado de cosas perenne. A su vez, había establecido que el esclavo (si queremos, el paria, el pobre o el miembro del Tercer Estado) tenía una obligación moral de sacudirse el yugo de la esclavitud y conducirse a su propia liberación.

14 Arendt, H. Sobre la Revolución. Alianza Editorial. Madrid, 2011. P. 44

15 Ib. P. 27. 
Sin embargo, al hablar de contrato social cabe preguntarse bajo qué criterio se reúnen los hombres entre sí, es decir, ¿qué tiene que tener un pueblo para decidir sobre un determinado gobierno? La respuesta de Rousseau es clara: para decidir estas cosas "convendría examinar el acto por el cual un pueblo es un pueblo"16.

Pues bien, para aclarar por qué un pueblo se vuelve un pueblo, se parte de la diferencia entre estado de naturaleza y estado civil. El primero hace referencia a la condición más hermosa del hombre para Rousseau, pues allí todo es paz y alegría; allí, recuerda el autor, el hombre es bueno. Solo cuando entra en sociedad es que se pervierte. Se trata, pues, de que el hombre entre en sociedad de tal forma que la propia máxima de Rousseau no se cumpla. Aquí es donde Rousseau establece el contrato social que habría de velar por que la bondad natural del hombre no desaparezca: "Encontrar una forma de asociación que defienda y proteja con toda la fuerza común a la persona y los bienes de cada asociado, y por la cual, uniéndose cada uno a todos, no obedezca, sin embargo, más que a sí mismo y permanezca tan libre como antes"17.

La facilidad con la que Rousseau expresa esta idea y la belleza de la misma podría llevarnos a pensar que la tarea es tan sencilla que parece que la humanidad habría derrochado siglos y siglos sin ella. Sin embargo, la frase misma encierra una dificultad esencial, una contradicción o una paradoja (de las que tanto gustaba precisamente usar Rousseau). No obstante, el contrato tiene unas cláusulas exactas que no se pueden vulnerar. La idea misma de su incumplimiento se convierte en el problema esencial del contrato, pues, si se incumple, los participantes recobrarían su libertad natural. Ahora bien, "[e]stas cláusulas, bien entendidas, se reducen todas a una sola: la enajenación total de cada asociado con todos sus derechos a toda la comunidad. Pues, en primer lugar, dándose cada uno todo entero, la condición es igual para todos, y siendo igual para todos, ninguno tiene interés en hacerla onerosa para los demás" ${ }^{18}$.

De esta manera, Rousseau fija como la tarea esencial de un Estado conciliar la libertad individual con la libertad de todos, enajenarla y recibirla nuevamente bajo el prisma de la universalidad. Lo paradójico es evidente: "dándose cada uno a todos no se da a nadie", esto es, ¿cómo entender la entrega total a la totalidad y no perderse en ella? Necesariamente, para superar esta paradoja, Rousseau debe postular algún elemento que, al menos, sea más evidente y más útil que el "nadie" al que uno

16 Rousseau, J.J. op. Cit. P. 269.

17 Ib. P. 270.

18 Ídem. 
se entrega. Este elemento es la "voluntad general": "Cada uno de nosotros pone en común su persona y todo su poder bajo la suprema dirección de la voluntad general; y recibimos del cuerpo a cada miembro como parte indivisible del todo" 1 .

\section{Igualdad y soberanía}

¿Qué es la voluntad general? Quizá la conciencia de la totalidad reflejada sobre sí misma; es decir, el para qué de la entrega de la libertad hacia algo más grande que el individuo, pero que incluye al individuo mismo. Como tal, al caer todos y cada uno bajo la voluntad general, los miembros devienen ciudadanos al más puro estilo de la democracia ateniense, esto es, "como participantes en la autoridad soberana" 20 (y la igualdad aparece aquí en toda su dimensión). En efecto, la voluntad general solo puede tener sentido si la expresión de mi voluntad coincide con la de todos, de modo tal que, si no suponemos que la razón es la misma en todo miembro del contrato, no habría, ni remotamente, la posibilidad de la voluntad general. Por consiguiente, no se trata solo de ser iguales, sino de llegar a amar la igualdad misma.

A su vez, si los miembros del contrato se convierten en ciudadanos iguales, no queda otro remedio que identificar la voluntad general con una forma de gobierno que permita que las cláusulas del contrato puedan efectuarse. La soberanía, para Rousseau, es el cuerpo político que emana del contrato, pero no se podría especificar (si lo tomamos en su forma inmediata) si el soberano ha de ser una persona específica o si, en realidad, cualquier miembro del contrato podría ejercerla.

Robespierre, en lo que refiere a su labor teórica -que desde luego recibe una clara influencia de Rousseau- postula que si queremos que haya igualdad (y que la voluntad general sea efectiva) solo cabe la democracia. No basta solo la igualdad, porque para Robespierre la democracia sin virtud no es nada. Pero ¿bajo qué régimen de gobierno se pueden dar la igualdad y la virtud? "En la monarquía no conozco más que a un individuo que pueda amar a la patria y que para ello no necesite de ninguna virtud: el monarca" ${ }^{21}$. Nada más lógico: el monarca ama su patria porque es suya, en cambio el súbdito ¿para qué amaría lo que no puede poseer? En la aristocracia el argumento es parecido, salvo que, en vez de tener un

19 Ídem.

20 Ib. p. 271.

21 Robespierre, Maximilian. Virtud y terror. Akal. Madrid, 2007, p. 216. 
amante, tendríamos varios. Aunque, nuevamente, en ese amor solo entran los aristócratas, el pueblo queda igual: sin virtud y sin igualdad. Además, la virtud que el monarca o los aristócratas imponen al pueblo ¿tendría sentido para él? Evidentemente, en la línea que seguimos aquí, tal virtud solo sería válida para los que tuvieran alma de esclavos: si tenemos dos clases contrapuestas y una manda sobre la otra, la virtud no puede ser la misma para ambos. La clase dirigente impone una ideología que la clase dirigida no puede aceptar de ningún modo, salvo que ame sus propias cadenas. Por eso, para Robespierre, solo hay igualdad y virtud en la república: "Como la esencia de la república o de la democracia es la igualdad, de ahí se sigue que el amor a la patria incluye necesariamente el amor a la igualdad"22.

Volviendo a Rousseau, tenemos que la soberanía es ejercida por la voluntad general y que esta no puede atentar contra sí misma so pena de caer en contradicción: "como el cuerpo político o el soberano no sacan su ser sino de la santidad del contrato, no pueden nunca obligarse, ni siquiera frente a otro, a nada que derogue este acto primitivo" 23 .

Hemos de tener en cuenta que las líneas aquí expresadas pueden obedecer al ejercicio teórico de un filósofo haciendo cuentas con la realidad. Pero si atendemos a la influencia de Rousseau en la Revolución francesa, no podemos sino notar que la república que emana del contrato social tiene una clara significación histórica: a saber, realizarla en la posibilidad de su perfección. De ahí que los revolucionarios franceses, si querían tomar nota de cómo dirigir la república (o la misma revolución), tuvieran que hacer sus cuentas con la teoría misma. La soberanía de la que habla aquí Rousseau no puede ser una mera fantasmagoría, sino que, para nuestro bien o para nuestro mal, debe ser representada por alguien que, como mínimo, cumpla con la exigencia del pacto.

Se trata, entonces, de un tema de legitimidad y, por ello, ¿qué es lo que hace legítima la política? En principio, esta se encuentra en el cuerpo político que es a su vez gobernado por leyes. Las leyes o el gobierno de las leyes es lo que dota de sentido a la legitimidad en tanto que las leyes emanen de la voluntad de los ciudadanos; por ello, escribe Abellán, "la legitimidad consiste en estar vinculado a la voluntad de los ciudadanos, que se manifiesta en las leyes, las cuales son asunto de la voluntad general, que es precisamente donde los ciudadanos como tales se

22 Ib. P. 215.

23 Rousseau, J.J. Op. Citatum. p. 272. 
funden en una persona pública"24. El gobierno legítimo, por ello, es aquel que hace cumplir las leyes que surgen de la ciudadanía. En consecuencia, la tarea del gobernante no puede ser arbitraria.

La naturaleza de la obediencia, es decir, el hecho de que los ciudadanos obedezcan y que esta idea no sea limitante de la libertad, responde al hecho de que la ley representa el carácter de la libertad de cada ciudadano, pues de él es que emanan estas. El poder soberano, por consiguiente, emana de la sociedad, de la voluntad general. A este propósito escribe Jouvenel que "el proceso se desarrolla en dos estadios: mediante un primer acto, los individuos se constituyen en pueblo y por un acto subsiguiente se dan un gobierno. De modo que el derecho total, la soberanía, que en los sistemas anteriores la otorgaba el pueblo al crearla, aquí la crea sin otorgarla, conservándola para sí a perpetuidad"25. La obediencia, por ello, no habría de ser algo forzado, pues el ciudadano conserva la soberanía, ni algo que en modo alguno contradiga las leyes ${ }^{26}$, pues ello contradice el espíritu del ciudadano.

De este modo, ¿quién podría hacerse cargo de la soberanía? Al responder esta pregunta, empezamos a notar el conflicto que se da en el ejercicio del poder. La lectura de Micromegas de Voltaire resulta provechosa a la hora de definir la naturaleza humana, en el sentido de que no podemos encontrar a dos personas que coincidan en una opinión, de la misma forma que es casi un milagro encontrar a dos personas que tomen el café igual. Por eso, Rousseau distingue entre una voluntad particular del ciudadano y lo que sería esa misma voluntad respecto a la voluntad general. Sin embargo, a pesar de que pueda haber una distinción en este ejercicio de las voluntades, la situación no debe generar ningún conflicto, porque la voluntad general prima sobre la particular. Así, de presentarse un punto de vista distinto, en lo que concierne a lo general (aun cuando no había quedado claro que era aquello de lo general mismo), rápidamente se ofrece una solución tajante: "Para que el pacto social no sea un formulario vano, implica tácitamente el compromiso, único, que puede dar fuerza a los otros, de que el que se niegue a obedecer a la voluntad general será obligado a ello por todo el cuerpo; lo cual no significa otra cosa sino que se le obligará a ser libre"27.

24 Abellán, Joaquín. Conceptos políticos fundamentales. Política. Alianza Editorial. Madrid, 2012, p. 216.

25 De Jouvenel, Bertrand. Sobre el poder. Unión Editorial. Madrid, 2017, p. 87.

26 En este sentido, la voluntad general es, así considerada, algo ciertamente atractivo, pues, en efecto, si un particular (ciudadano o facción) lograra, por así decirlo, la identificación plena con la voluntad, el poder obtenido sería pleno.

27 Ib. P. 273. 
La voluntad general supone que los miembros del pacto han entrado en el estado civil; es decir, han salido de la naturaleza y ahora tienen un espacio público en el que desarrollarse junto a otros seres racionales e iguales. El cambio de un estado al otro supone que antes, en la naturaleza, el sujeto se ponía sus propios límites, mientras que en la sociedad civil los límites son los de la voluntad general. Se reconoce una ganancia en este tránsito: "podría agregarse a las adquisiciones del estado civil la libertad moral, única que hace al hombre verdaderamente dueño de sí, pues el impulso del simple apetito es esclavitud, y la obediencia a la ley que uno se ha prescrito es libertad"28.

La ley, pues, permite (o ha de permitir) que el tránsito a la sociedad civil no sea óbice para una pérdida de la libertad, sino para que, antes bien, la conserve y mejore. A su vez, el hombre justo y bueno, al prescribir su propia ley, ¿̇no estaría en perfecta armonía con la ley que se ha de derivar de la voluntad general? En caso contrario, que el sujeto prescriba una ley que no coincida con la voluntad general caería en una contradicción y, por lo que ya habíamos visto, habría de ser obligado a cambiarla en pro de la totalidad. Como se ve, el problema se hace patente: ¿cómo puede coincidir la voluntad de un individuo con la voluntad de todos?

La respuesta habría de encontrarse, de alguna manera, en la expresión de que los hombres, desde la igualdad que los hace humanos, si piensan con buen juicio y al margen de cualquier particularismo, habrían de llegar a las mismas conclusiones respecto de la ley. Aunque las diferencias sociales o económicas sean exorbitantes, para Rousseau esto no es un problema: la justicia es igual para todos, por lo que todos habrán de reconocerla.

Si el problema fuera tratado económicamente y, mediante alguna suerte de magia, se lograra que las diferencias económicas entre los miembros del pacto fueran mínimas, el problema se resolvería fácilmente. Pero, no siendo así, los intereses de clase conducen a que la misma justicia pierda su universalidad y se entre, inevitablemente, en una serie de conflictos entre clases. Ahora bien, para Rousseau esto solo supone que ha habido un error en el pensamiento y se trata, ahora, de hacer ver a los que se equivocan de la necedad de su concepción de la justicia. Sin embargo, ¿quién detenta la verdadera noción de ley? La soberanía que emana de la voluntad general.

28 Ib. P. 274. 


\section{Voluntad general y conflicto entre facciones}

Para Rousseau, la voluntad general es la expresión de la totalidad que se sabe a sí misma como totalidad, en cuyo caso la voluntad general es consciente de su infalibilidad. La soberanía, por ello, es tanto inalienable como indivisible. El soberano, en tanto que "ser colectivo", no puede ser más que él mismo, por lo que no puede enajenar su soberanía, so pena de quedarse en nada. Y es indivisible porque de no serlo no habría voluntad general, sino voluntades particulares. Aunque Rousseau, más exactamente, entiende que no se puede romper el principio de la soberanía, aunque sí su objeto, por lo que puede hablarse de una separación de poderes, esto es, el poder legislativo y el ejecutivo.

Entonces, al ser la voluntad general una entidad perfecta, ¿puede equivocarse? En la respuesta a esta pregunta encontramos la crítica de Berlin a Rousseau, a quien considera "enemigo de la libertad". "La voluntad general", escribe Rousseau, "es siempre recta y tiende siempre a la utilidad pública" ${ }^{29}$. Pues bien, si se diera la igualdad absoluta entre los miembros, es decir, si la totalidad fuera un "nosotros" perfecto, no habría nada que añadir. Sin embargo, tal cosa no es ni remotamente evidente, dado que la naturaleza humana tiende a creerse sus ideas, convengan o no estas a la totalidad. Y Rousseau, que no puede negar esta realidad, supone que no es que el pueblo en el ejercicio de su pensamiento se equivoque, sino que, más bien, puede ser engañado y, dada tal circunstancia, puede errar en sus consideraciones sobre la voluntad general.

Se barrunta aquí, entonces, una lucha ideológica entre el verdadero pensar que conduce a la libertad y un falso pensar que conduce a la escisión del pacto. La verdad está clara y no es otra que la que emana de la voluntad general, pero esta verdad ¿coincide con el pensamiento predominante? En realidad no, y por ello no hay que extrañarse ante la idea de que el pensamiento de Rousseau entre en un proceso al que denominamos "Ilustración" y que supone, cuanto menos, un enfrentar la ideología dominante y situar la verdadera ideología que se desprende del pensar y observar. A este proceso le decía Kant "alcanzar la mayoría de edad": ser capaz de pensar por sí mismo; Hegel entendía aquí la lucha de la razón contra la superstición.

29 Ib. P. 280. 
Hay, pues, una "verdad verdadera" que conduce a la verdadera ideología y una "verdad falsa" que es contra la que hay que combatir. Como vemos, Rousseau, a fin de cuentas, sería un filósofo que habría tenido la suerte de encontrar la verdad, y los demás simplemente serían los afortunados que tendrían la dicha de escucharlo y comprenderlo. Con todo, al margen de lo irónico de la frase anterior, lo cierto es que en la Revolución francesa Rousseau se convierte en un pilar inatacable y casi perfecto, sobre todo si tenemos en cuenta que incluso María Antonieta le dedicó horas de estudio a sus obras.

La voluntad general, por ello, es la expresión de la verdad y supone -en tanto que haya comunidad con ella- la mayoría de edad y la lucha contra las supersticiones. Aquí verificamos que Rousseau no andaba desencaminado al insistir en la necesidad de la educación, dado que, de hecho, la superstición es lo que queda cuando los ciudadanos no han sido ilustrados. Pero más allá de la desdicha de una sociedad inculta está el interés en hacer ver, desde la voluntad general, cómo se "eleva" a los sujetos desde su base supersticiosa a la cota de verdad que une a los hombres en la voluntad general. La idea, si la hacemos explícita, resulta convincente: educar a los hombres es darles una vida verdadera.

Entonces, "si, cuando el pueblo, suficientemente informado, delibera, no tuvieran los ciudadanos ninguna comunicación entre ellos, del gran número de pequeñas diferencias resultaría siempre la voluntad general, y la deliberación sería siempre buena" 30 . Lo cual vendría a ser parecido a la idea de que en un aula todos los alumnos han estudiado una determinada lección y, al ser examinados, todos sacan buena nota. Por ello, para Rousseau, la voluntad general no yerra nunca. La cuestión es velar por que los miembros del contrato se eleven a la altura de las circunstancias. Solo que una cosa es la teoría y otra la práctica, y, por ello, a Rousseau no le pasa desapercibido que, ante la voluntad general, se forman facciones.

¿Qué son las facciones? Son los distintos grupos que se asocian en torno a lo que para ellos ha de ser la voluntad general, diluyendo su significado universal en varios particulares, o bien "asociaciones parciales a expensas de la grande" ${ }^{1}$. La facción representa un sentido de la verdad que se opone a otros sentidos, pero que a su vez se presenta como la única verdad; por eso, para Rousseau, "la voluntad de cada una de estas asociaciones resulta general en relación a sus miembros, y particular en relación al Estado"32.

30 Ídem.

31 Ídem.

32 Ídem. 
Para notar mejor qué es lo que vamos a exponer a continuación, destacamos una doble suposición sobre el pacto social. En primer lugar, siguiendo a Rousseau, encontramos que una serie de hombres, de los cuales no podemos especificar su procedencia, se reúnen y se asocian en torno a la voluntad general. En segundo lugar, es posible que estalle una revolución y, por la transformación radical a la que se conduce a la sociedad, los hombres (ahora libres) se reúnen para conformar la voluntad general. De la primera suposición poco podemos decir sin caer en una abstracción, pero quizá, de darse, no habría conflicto (a favor de ella encontramos la idea del buen salvaje y la expresión de pueblos que, sin tener Estado, viven en armonía). Pero de la segunda no podemos suponer que la expresión de la voluntad general emerja sin conflicto.

Una revolución es el tránsito de un sistema de relaciones de poder, de relaciones sociales y relaciones económicas, en general, de toda suerte de relación, a otro sistema de relaciones de poder, relaciones sociales, etc. Tránsito que generalmente no es pacífico, sino que se presenta de forma abrupta, impetuosa; en una palabra, violenta. ¿YY por qué se opera la revolución con violencia? Porque al caer la estructura del poder, todos son igualmente válidos para detentarlo, por lo que proliferan las facciones y la voluntad general pasa de una universalidad a una particularidad que se comprende a sí misma como universal. Aquí viene a cuento recordar que, para Hegel, en la Revolución francesa "lo que ocurre es que la facción triunfante se llama gobierno"33.

El problema de la revolución es la voluntad general que el propio Rousseau había descrito elocuentemente y de la que habíamos dicho que no se podía equivocar. Por tanto, detentar el poder es ser representante directo de la voluntad general y, entonces, la lucha entre las facciones es prácticamente una lucha metafísica por la verdad con resultados sangrientos ${ }^{34}$. Berlin, en La traición a la libertad, considera que Rousseau, a la postre, es un abanderado de la tiranía, incluso cuando él mismo no se diera cuenta. El caso es que, desde la lógica de la revolución, todas las facciones son poseedoras de la verdad y son la representación (por lo menos ideal) de la voluntad general y la verdad. Su misión, entonces, es anunciar su esencia como la verdad misma y su actividad es reiterar ante todos que, siguiendo su causa, se sigue a la verdad: "porque si ellos supieran lo que en realidad desean, buscarían lo que yo busco" ${ }^{35}$. La

33 Hegel, G.W.F. Fenomenología del espíritu. Fondo de Cultura Económica. Madrid, 1999, p. 347.

34 Sin que necesariamente tenga una condición tan universalista como la voluntad general, otro tanto podría decirse del concepto de "dictadura del proletariado". En efecto, la dictadura del proletariado implica que los proletarios son los que mandan y, en teoría, la palabra del obrero es palabra de ley. Sin embargo, más allá de la teoría, ¿realmente los obreros llegarían a ser los dictadores o, por el contrario, tendrían que aceptar un poder distinto del suyo?

35 Berlin, Isaiah. La traición a la libertad. Seis enemigos de la libertad humana. Fondo de cultura 
consecuencia es inevitable: si ellos no lo saben, el gobierno es el encargado de ensenárselos. ¿Cómo? Todos los medios son buenos para lograr la verdad, desde la práctica de la virtud hasta el terror. Por eso Rousseau, al hablar de la voluntad general, no se dio cuenta de que, en el caso de una revolución, a la verdad no se llega por el raciocinio, sino por la lucha. Por eso, la "doctrina central de Rousseau [...] conduce a la auténtica servidumbre, y por este camino, desde la deificación del concepto de libertad absoluta, alcanzamos gradualmente la noción de despotismo absoluto"36.

Pero ¿cómo se pasa de la libertad al despotismo? Nada más fácil si se piensa con coherencia desde una revolución: el contenido de la voluntad general no podía ser dado de antemano, porque en realidad no es fácil encontrar a dos hombres que piensen igual, e incluso, cuando más o menos piensan igual, los matices que los separan a veces son insalvables. Por ello, el que consiga más poder tiene que sugerir (si damos al menos la oportunidad a la humanidad de que se entienda hablando) al que está en contra de su posición de que está en un error. Pero si no es capaz de verlo, Rousseau había dejado claro que se podía obligar al que no es capaz de ver la verdad o la libertad a que la vea bajo el prisma de la voluntad general. No obstante, como la voluntad general ha devenido en la voluntad de una sola facción, esta tiene la potestad de obligar a toda una nación a ver las cosas de una manera determinada. Berlin, por esto mismo, escribe: "el mal que hizo Rousseau consistió en lanzar la mitología del verdadero yo, en nombre del cual se me permite coaccionar a la gente" ${ }^{37}$. Y no solo eso: "los jacobinos, Robespierre, Hitler, Mussolini y los comunistas: todos ellos emplean este mismo método de argumento, de decir que los hombres no saben lo que en realidad desean; y por tanto, al desearlo por éstos, al desearlo en nombre de ellos, estamos dándoles lo que en algún sentido oculto, sin saberlo ellos mismos, ellos 'en realidad' desean" ${ }^{\text {" }}$.

\section{El terror, la virtud y la libertad absoluta}

¿Sabe el pueblo lo que le conviene? En la lógica que venimos explicando, parece que no. Sin embargo, sacando aquí la cara por Rousseau, este había dejado escrito que no se podía vulnerar a los miembros del pacto social. Si bien es cierto que había permitido coaccionarlos, no se había hablado de violentarlos o matarlos.

económica. México, 2002, p. 71.

36 Ib. P. 73.

37 Ib. P 74.

38 Ib. P. 72. 
Cosa distinta ocurre con quienes, en el plano de la realidad, se sitúan como representantes de la voluntad general. En efecto, llegar al poder no ha sido siempre cuestión de representar a la mayoría, sino de haber sido más listo que otros y haber sabido interpretar mejor que otros las circunstancias (es el caso de Lenin, sin ir más lejos). Pero una vez se está en el poder, se presenta un conflicto: ¿cómo hago para que millones de personas consideren que mi expresión de la verdad es la única válida? La lógica de los acontecimientos históricos solo ha permitido una respuesta: mediante el terror.

Hegel dedica una parte de su Fenomenología del espiritu al análisis de la Ilustración (como lucha contra la ideología) y de cómo -resultado del contexto real de la Revolución francesa- se habla de la libertad absoluta que es la que surge al romper toda barrera en las ansias de la libertad de los individuos. Tal libertad no pide realización, sino que únicamente pide ser "el contemplar del sí mismo en el sí mismo"39.

Tal libertad supone, en la conciencia del ciudadano (y escribimos el término "ciudadano" para mantener la tónica del aquel tiempo), la representación de que su saber y su ser es la expresión de la voluntad general, es decir, la elevación de lo particular a lo general en la medida que tal universalización es producida por la situación sin precedentes a la que se llega en la revolución, esto es: la libertad, la igualdad e incluso la fraternidad. Caído el Antiguo Régimen, la coacción contra los individuos no sería ocasionada por un "superior" -en el sentido de que un noble tenía una posición superior a la de un plebeyo-, sino que tendría que venir de un igual, y ¿qué igual podría decirme qué es lo justo o lo injusto? ¿Qué igual tendría derecho a coaccionarme? Como tal, nadie de forma individual puede ejercer presión sobre mí... tendría que ser algo derivado del pacto, la voluntad general como tal. Ahora bien, ¿esta voluntad general es algo distinto de mi forma de pensar? Se mire por donde se mire, el conflicto es evidente e inevitable: "el mundo es, para la conciencia, simplemente su voluntad, y ésta es voluntad universal”" 40 .

El resultado son las facciones y de estas puede decirse no solo que son desavenencias de la voluntad general respecto de sí, sino que la facción no busca una suerte de diálogo con las otras facciones para redimirse en la voluntad general y darle validez, sino que se supone como la única que garantiza eso universal a todas las facciones e individuos que entran en juego. Para Hegel, la libertad absoluta que se presenta en los ciudadanos fluye a un quehacer negativo que

39 Hegel, G.W.F. Fenomenología del espíritu. Fondo de Cultura Económica. Madrid, 1999, p. 344.

40 Ib., p. 344. 
entra en la existencia de modo que cada conciencia singular se eleva de la esfera que le había sido asignada y no encuentra ya en esta masa particularizada su esencia y su obra, sino que capta su sí mismo como el concepto de la voluntad, capta todas las masas como esencias de esta voluntad y sólo puede realizarse en un trabajo que es trabajo total ${ }^{41}$.

La expresión más pura de esta libertad absoluta, por lo tanto, no es otra que la imposición de una voluntad que rige y gobierna como universal, aun siendo particular. El que accede al poder en una revolución entiende que su voluntad no es particular, sino universal, en el sentido en que antes Berlin criticaba a Rousseau. Por eso, si su voluntad se ve teñida de particularidad, aquella necesita afirmarse para volver a la universalidad. Para Hegel, la libertad absoluta no tiene más objeto que el afirmarse, "de donde se sigue que no puede arribar a ninguna obra positiva" ${ }^{2}$. De hecho, el gobernante en la revolución tiene un conflicto en su obrar, pues cree que su visión o voluntad es la voluntad de todos, pero tal creer conduce a un extrañamiento, a un desvarío, pues lo que sucede es más bien todo lo contrario: las distintas facciones o los distintos ciudadanos no se reconocen en esa voluntad ni el gobernante se reconoce en ellos y, por ello, "[n]inguna obra ni acto positivos puede producir la libertad universal; a dicha libertad sólo le resta el obrar negativo; es solamente la furia del desaparecer" ${ }^{\text {³ }}$.

Con ello, tenemos que "la revolución es como Saturno, se come a sus hijos", como decía Vergniaud. La lógica de la revolución supone la inauguración de la voluntad general, pero sus consecuencias no son previsibles. Las revoluciones y los revolucionarios son sometidos al juicio de la historia, dado que en su proceso todo es posible. Notemos que en el marco de la Revolución francesa, Danton fue guillotinado por protestar contra el terror. Pero claro, protestar contra el terror era protestar contra Francia entera. Danton, por hablar, se convirtió en sospechoso. De igual manera, en la Unión Soviética de Stalin, Trotsky fue asesinado en México.

Pero el terror, por otro lado, ¿es totalmente innecesario? En realidad, si queremos tomarnos en serio una revolución sabemos desde el comienzo que se han de operar cambios estructurales de carácter radical. ¿Qué hacer entonces con los que se oponen a la revolución o a esa voluntad general que se va gestando? Hacerles ver que están en un error y que deben ceder sus intereses particulares a los

41 Ib., p. 345.

42 Ídem.

43 Ib. P. 346 
generales no parece ser una opción, por lo que más tarde o más temprano habrá represión sin que se sepa qué alcance tendrá ${ }^{44}$.

Robespierre, personaje difícil de enjuiciar, comprendió que si la revolución y sus logros habían de mantenerse era necesario el terror, es decir, matar al número suficiente de personas para no entorpecer la marcha revolucionaria. Pero, por otro lado, también comprendió que matar por matar no era tampoco una solución, motivo por el cual el terror habría de ir acompañado de virtud. En este sentido, el hombre conocido como "el altar de Francia" -como referencia a su pureza moralnos dejó esta frase en su discurso del 17 de pluvioso del año II: "Si el principal instrumento del Gobierno popular en tiempos de paz es la virtud, en momentos de revolución deben ser a la vez la virtud y el terror: la virtud, sin la cual el terror es funesto; el terror, sin la cual la virtud es impotente. El terror no es otra cosa que la justicia rápida, severa e inflexible; emana, por lo tanto, de la virtud"45.

Establecer la libertad y la igualdad no es cosa fácil. La historia da sonadas pruebas de ello. A veces, los que pretenden liberarnos de las cadenas de la esclavitud nos conducen a la fría sombra de la muerte.

\section{Referencias}

Abellán, J. (2012) Conceptos políticos fundamentales. Política. Alianza Editorial. Madrid. Arendt, H. (2011) Sobre la Revolución. Alianza Editorial. Madrid.

Berlin, I. (2002) La traición a la libertad. Seis enemigos de la libertad humana. Fondo de cultura económica. México.

De Jouvenel, B. (2017) Sobre el poder. Unión Editorial. Madrid.

Fichte, J. G. (2002) Algunas lecciones sobre el destino del sabio. Itsmo. Madrid.

Furet, Frances y Ozout, Mona (eds.) (1989). Diccionario de la Revolución Francesa. Alianza Editorial. Madrid.

Hegel, G.W.F. (1999) Fenomenología del espíritu. Fondo de Cultura Económica. Madrid. Kojeve, A. (2012) La dialéctica del amo y del esclavo en Hegel. Leviatan. Buenos Aires. Robespierre, M. (2007) Virtud y terror. Akal. Madrid. Rousseau, J. J. (2014) El contrato social. Gredos. Barcelona.

44 En este sentido, se remite aquí a cualquier estudio que establezca las cifras de las distintas revoluciones que han acontecido en la historia reciente.

45 Robespierre, Maximilian. Virtud y terror. Akal. Madrid, 2007, p. 220. 